\title{
Consumer response towards an accreditation system for hiking trails
}

\author{
Mrs Liandi Slabbert \\ South African National Parks \\ 643 Leyds street, Muckleneuk, Pretoria. \\ liandi.slabbert@sanparks.org \\ Co-author: Dr Elizabeth Du Preez \\ Department of Marketing and Communication Management \\ University of Pretoria \\ Cnr of Lynnwood road and Roper street, Hatfield Pretoria. \\ elizabeth.dupreez@up.ac.za
}




\begin{abstract}
Accreditation has a significant role to play in the upholding of quality and sustainability standards in the supply of tourism and leisure products. Accreditation systems, although widely used in tourism accommodation, services and sustainability practices, relate primarily to the traditional market of tourism with very few systems addressing the needs of adventure and nature-based tourism. When applied in the context of hiking, accreditation may materially impact the way trails are managed and marketed, leading to perceptions of quality and credibility amongst consumers. Trail owners and policymakers often question whether a demand for accreditation systems exists amongst consumers and to what extent such implementation could improve participation in the industry. While the work by various authors in the wider context of tourism provide some context as to the influence of accreditation systems on consumers' decision making and buying behaviour, in the case of hiking products, this has not previously been investigated. In fact, the unique components of consumer behaviour and consumer decision making in hiking has not been clearly defined at an academic level. Current literature provides no insight into the influence of accreditation systems in current and potential consumers' decision making regarding the consumption of hiking products. This study took a quantitative approach in the form of a survey research strategy to measure the importance of and future intended response towards trail accreditation, as determined by consumers from two different populations: hikers and nonhikers. This was achieved by presenting a hypothetical country-wide implementation of a case study accreditation system to respondents. The study demonstrates a link between accreditation and consumer decision making and the future uptake of hiking tourism amongst both hikers and non-hikers. The findings from this paper contribute to bridging numerous gaps in literature in the fields of adventure and nature-based tourism.
\end{abstract}

Keywords: Hiking, nature-based tourism, adventure tourism, accreditation, ecolabels, consumer behaviour, consumer decision-making. 


\section{$\underline{\text { Introduction }}$}

The leisure activity commonly referred to as hiking in South Africa, is also known by various other names; often used synonymously and sometimes interchangeably in countries across the globe. These include but are not limited to: walking, bushwalking, outdoor walking, rambling, tramping, backpacking, trailing and long distance trailing, trekking and hill walking. International travel marketers agree that South Africa with its estimated 10224 kilometres of footpath, offers some of the most spectacular hiking opportunities in the world (Lonely Planet, 2015; Placestoseeinyourlifetime.com, 2014; Walkopedia, 2015; hellawella.com, 2015; BuzzFeed, Inc., 2015). Hiking trails such as the North Drakensberg Traverse in South Africa ranks amongst the world's best (National Geographic Society, 2014).

One of the biggest threats to the industry however is the deterioration in the quality of trails. The Hiking Organisation of Southern Africa (HOSA) believes a significant proportion of trails in South Africa no longer comply with normal hiking requirements due to challenges such as poor accommodation, safety issues, poor or no maintenance, environmental degradation, and inadequate water supply (A. Bossert, personal communication, March 3, 2013). Other challenges identified by Tourism KwaZulu-Natal include the lack of signage on trails, poor mapping skills and polluted water sources (all pointing to a lack of maintenance or planning by trail owners) as well as crime-related incidences (K.Kohler, personal communication, March 2, 2015)

In 2006, the need for a quality control system was seemingly met with the implementation of the Green Flag Accreditation System (Green Flag), an independent body through which trails are assessed according to its difficulty grading, safety levels, service and trail facilities, accommodation, the type of environment the trail is set in as well as the environmental management of the trail (Green Flag Trails, 2015). Green Flag, accepted as the official accreditation system of HOSA, is the only trail accreditation system in Africa and receives support from the World Trails Network (WTN) as well as the major conservation agencies in South Africa (including South African National Parks, KZN Ezemvelo Wildlife and Cape Nature). To date, implementation has been slow with approximately 60 trails having gone through accreditation both in South Africa as well as other parts of the world. Marketing activities of Green Flag have been limited due a lack of resources and budget by the accreditation authority. Interest and support from governmental bodies such as the National 
Department of Tourism (DoT) as well as the Department of Environmental Affairs (DEA), has been lacking (M.L. Hugo,.personal communication, February 28, 2015).

The questions often posed by trail owners and policymakers in their consideration of adoption or support of such scheme, are whether a demand for such quality control system exists amongst consumers and whether the implementation of such system could significantly improve participation in the industry. While the work by various authors in the wider context of tourism provide some context as to the influence of accreditation systems on consumers' decision making and buying behaviour, in the case of hiking products, this has not previously been measured.

\section{$\underline{\text { Literature review }}$}

The manifestation of consumer demand for an accreditation system is dependent on the acceptance of the system by a reasonable size of the market. Many suppliers, however, will not adopt such schemes before evidence of consumer demand cannot be presented. To ensure sustainability of the accreditation or certification scheme, a critical mass of at least $3 \%$ to $10 \%$ of the market is needed. The scheme would also need to be widely recognised amongst consumers to be effective (Lacher, 2012). Without such recognition, the case for a competitive advantage to suppliers would be difficult to prove (Leonard, 2011). Literature to suggest that a significant number of consumers proactively seek sustainable tourism certification is inadequate (Leonard, 2011; Lacher, 2012), often indicating towards disparate results when it comes to consumer response to for example, more sustainable and socially responsible practices (Chia-Jung \& Chun, 2014). A few studies, such as Marchoo et al., (2014), confirmed tourists' approval and recognition of accreditation systems such as that of the Green Globe 21. Some researchers however suggests that consumer demand for environmental brands takes decades to develop (Leonard, 2011), while others are of the opinion that the variety of ecolabels available today has left the consumer confused and have led to consumers becoming indifferent towards ecolabels (Font, 2002). The impact of tourism accreditation on individual tourists' buying behaviour remains largely undiscovered with only a few researchers exploring the topic (Buckley, 2002; Marchoo et al., 2014). Very little has been done academically to determine the impact of accreditation on consumer evaluations of tourism companies. In Australia, a survey of 155 tourists concluded that consumers do not 
pursue a product or service based on whether an operator is accredited (Foster, 2003). However, a significant percentage of consumers responded that they would make use of an accredited service provider if they were aware of its existence. Likewise, an exploratory study by Bergin and Jago (1999) found the accreditation of adventure tour operators, although positively received by consumers of adventure tourism products, would not necessarily result in consumers preferring an accredited product above a non-accredited one.

Evidence does exist for the fact that accreditation is a successful strategy to build consumer trust in the case of non-tourism products such as organic food and fair-trade labelled products. Research to demonstrate this link within tourism and leisure is however lacking. Some contend that accreditation systems such as ecolabels provide consumers with information that allow alternative choices (Buckley, 2002). A recent contribution to the subject is that of Marchoo et al. (2014) who has shown that accreditation has significant impacts on perceived tour value, trust, and tour booking intention. Tourists may regard accreditation systems as a sign of quality in their quest for satisfaction, however consumer attitude is not a reliable predictor of future buying behaviour (Leonard, 2011).

Research investigating the impact of accreditation on consumer decision making in general is insufficient, with no literature exploring its impact in a hiking tourism context.

\section{$\underline{\text { Methodology }}$}

The study took a quantitative approach in the form of a survey research strategy to measure the influence of trail accreditation in decision making and buying behaviour, as determined by consumers from two different populations: hikers and non-hikers. The hiker population was defined as all individuals participating in hiking activities on trails within the borders of South Africa. The non-hiker population consisted of individuals who did not regard themselves hikers, but who display a strong interest in participation in at least one of the following activities offered within the borders of South Africa: nature-based tourism or outdoor recreational activities.

Since no reliable databases of the hiking population existed, the non-probability sampling method of self-selection was applied. The gatekeepers through which internet-mediated 
access was granted to both populations included hiking clubs based in South Africa as well as the South African National Parks' Wild Card membership programme. In addition, three local commercial entities that manufacture and sell outdoor recreational and sports apparel and equipment provided access to consumers from both populations.

The online structured questionnaire consisted of primarily closed-ended questions measuring consumers' response to an accreditation system in terms of decision making and future consumption patterns. A total of 1174 questionnaires were deemed usable.

Respondents were presented with a graphical representation of the key information points provided by Green Flag and asked to rate how their hiking activity levels (or lack thereof) would change if all trails in South Africa were accredited and a trustworthy description of trail attributes were available. Prior to presenting respondents with the key information outcomes of Green Flag, hikers' perceptions of the importance of trail accreditation in their decision making were measured to determine the need for such a system in general.

\section{$\underline{\text { Results }}$}

\section{Perceived importance of accreditation in consumer decision making}

Prior to presenting respondents with the key information attributes of Green Flag, hikers' perceptions of the importance of trail accreditation during decision making were measured on a five-point Likert scale, providing a baseline for determining the need of an accreditation system in hiking. The results indicated the majority of hikers (64\%) regard independent trail accreditation as important, very important or extremely important when deciding on which trails to hike. Almost a third of hikers (31\%) viewed it as a very important to extremely important consideration in decision making (Figure 1). 


\section{Figure 1: Importance of independent accreditation in decision making}

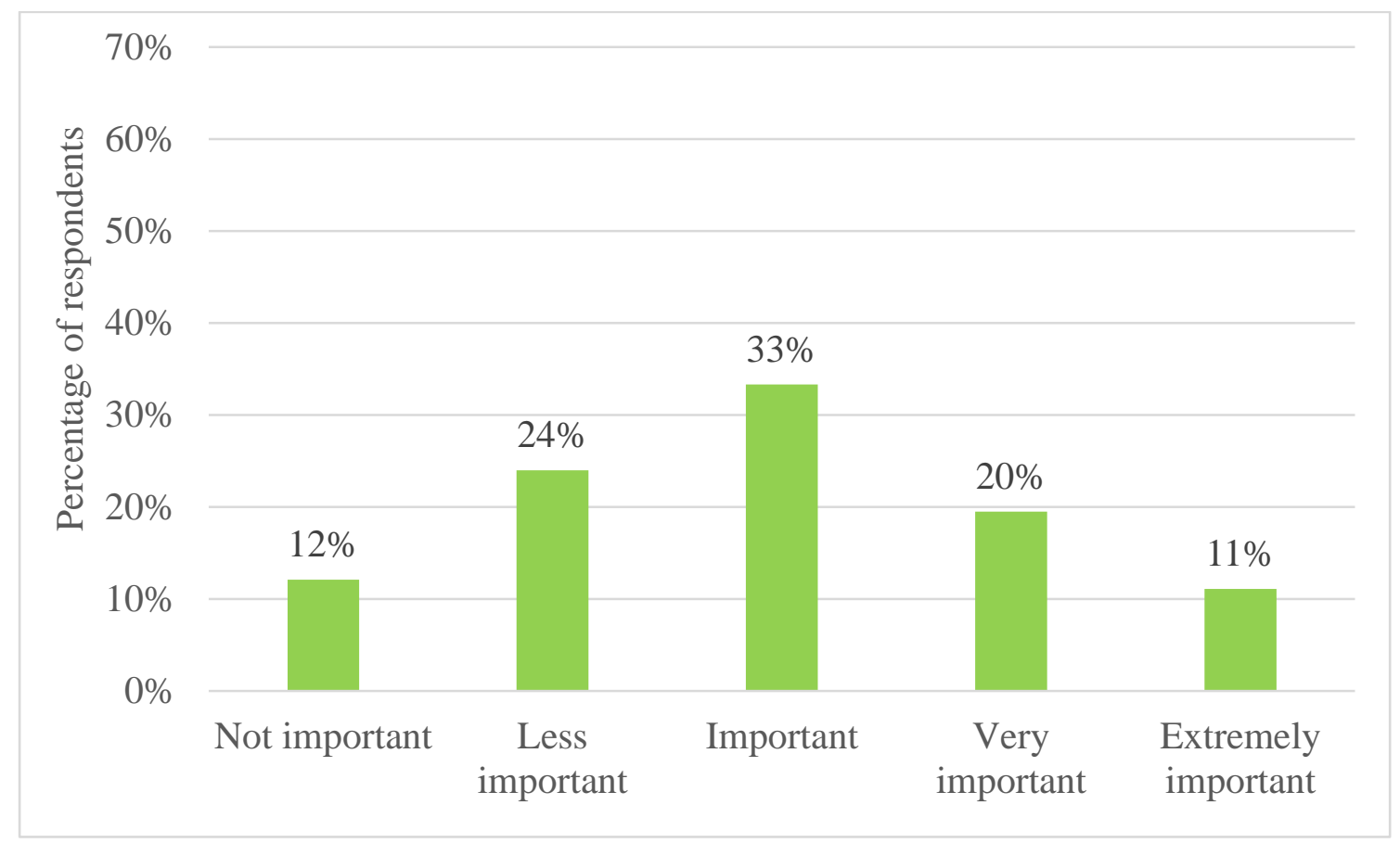

The level of hiking activity and the importance of accreditation

To test whether the importance of accreditation is influenced by a hiker's activity levels, the frequencies of each category of hikers, presented in a cross tabulation (Table 1), were tested for significant differences.

Table 1: Cross tabulation of importance of accreditation by frequency

\begin{tabular}{|c|c|c|c|c|c|}
\hline & & & Importance 0 & accreditation & \\
\hline $\begin{array}{l}\text { Hiking } \\
\text { activity }\end{array}$ & & & $\begin{array}{c}\text { Not } \\
\text { important or } \\
\text { of little } \\
\text { importance }\end{array}$ & $\begin{array}{l}\text { Important } \\
\text { to extremely } \\
\text { important }\end{array}$ & Total \\
\hline levels & Infrequent & Count & 174 & 366 & 351 \\
\hline & Frequent & Count & 150 & 201 & 540 \\
\hline & & Total & 324 & 567 & 891 \\
\hline
\end{tabular}

Using the non-parametric test of Pearson Chi-Square at a $1 \%$ level of significance $(\mathrm{p}=0.001)$, the null hypothesis, "There is no association between hiking activity levels and the level of importance of accreditation" was rejected (Table 2). 
Table 2: Association between importance of accreditation and frequency of hiking

\begin{tabular}{|c|c|c|c|}
\hline & Value & df & $\begin{array}{l}\text { Asymptotic } \\
\text { Significance } \\
\text { (2-sided) }\end{array}$ \\
\hline Pearson Chi-Square & $10.160^{\mathrm{a}}$ & 1 & .001 \\
\hline $\mathrm{N}$ of Valid Cases & 891 & & \\
\hline
\end{tabular}

a. 0 cells $(.0 \%)$ have expected count less than 5 . The minimum expected count is 127.64 .

b. Computed only for a $2 \times 2$ table

Note: Significant differences indicated in bold

There is therefore an association between hiking activity levels and the perceived level of importance of accreditation. We further observe that a larger proportion of infrequent hikers rank accreditation as important, very important or extremely important than frequent hikers (hiking six or more trails per year).

\section{Preferred booking channels and the importance of accreditation}

To test whether there is an association between the perceived level of importance of accreditation amongst hikers who book directly with trail owners and those who do not, we observe from the cross tabulation in Table 3 that, of those hikers who book directly through trail owners, a far bigger proportion rated accreditation as important compared to those who do not.

Table 3: Cross tabulation of the importance of accreditation by booking channel used

\section{Hikers who Hikers who do \\ book not book \\ directly with directly with Total \\ trail owners trail owners}

Accreditation rated as not important or of little importance

88

246

334

Accreditation rated as important, very important or extremely important 
The result of the Pearson Chi-square produces a $p$-value of less than 0.01 (see Table 4) and on that basis, we reject the null hypothesis of no association. An inspection of the differences between the actual frequencies (Table 3) indicates the proportion of hikers who book directly with trail owners and rated accreditation as important was greater than the proportion who rated accreditation as of no or little importance. Hikers who do not make use of third parties may require more information, thus placing more value on an accreditation system.

Table 4: Importance of accreditation by booking channel used

\begin{tabular}{|c|c|c|c|}
\hline & Value & df & $\begin{array}{l}\text { Asymptotic } \\
\text { Significance } \\
\text { (2-sided) }\end{array}$ \\
\hline Pearson Chi-Square & $15.571^{\mathrm{a}}$ & 1 & .000 \\
\hline $\mathrm{N}$ of Valid Cases & 926 & & \\
\hline
\end{tabular}

a. 0 cells $(.0 \%)$ have expected count less than 5 . The minimum expected count is 115.42 .

b. Computed only for a $2 \times 2$ table

Note: Significant differences indicated in bold

\section{Potential influence of accreditation on future purchase behaviour}

All respondents were asked to rate if, and to what likelihood their decision regarding hiking or current hiking activity levels would change if all trails in South Africa were accredited and a trustworthy description of trail attributes were available such as in the case study provided. Figure 2 represents a visual representation of the key information attributes made available by Green Flag to consumers post accreditation. Respondents were asked to consider the contents of the image when answering the following question: "If all trails in South Africa were assessed by an independent body and a detailed description of each trail (as in the image provided) was available, how would this influence your future hiking activity/decision to hike?". 
Figure 2: Green Flag summary of trail attributes (Green Flag Trails, 2015)

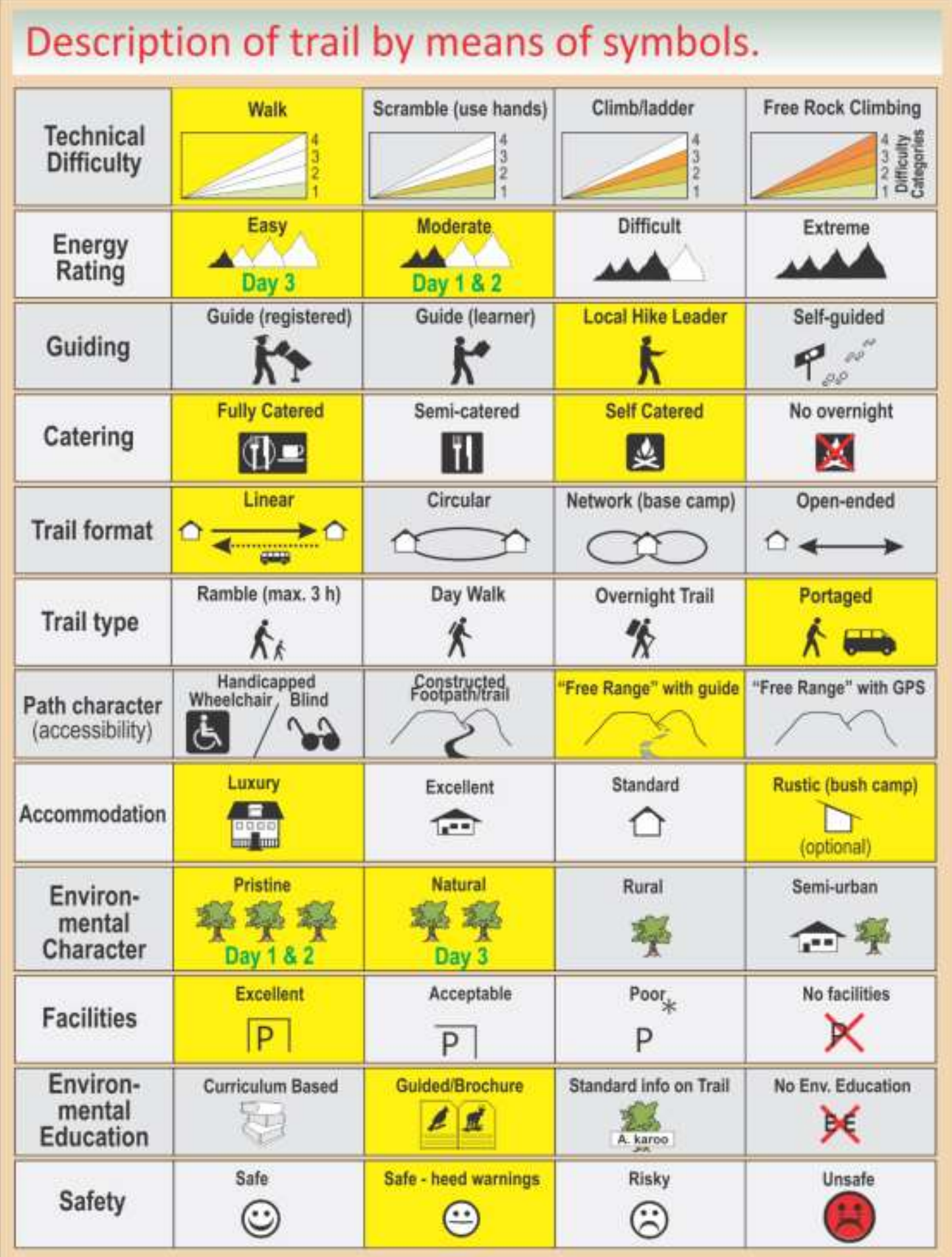

Relevant catagory for this particular trail 


\section{Non-hikers}

More than half $(57 \%)$ of non-hikers were willing to reconsider their decision regarding hiking, should all trails in South Africa be independently accredited (Figure 3). An additional $23 \%$ were even convinced the presence of trail accreditation would persuade them into actual purchases of hiking tourism products.

\section{Figure 3: Influence of accreditation on decision making amongst non-hikers}

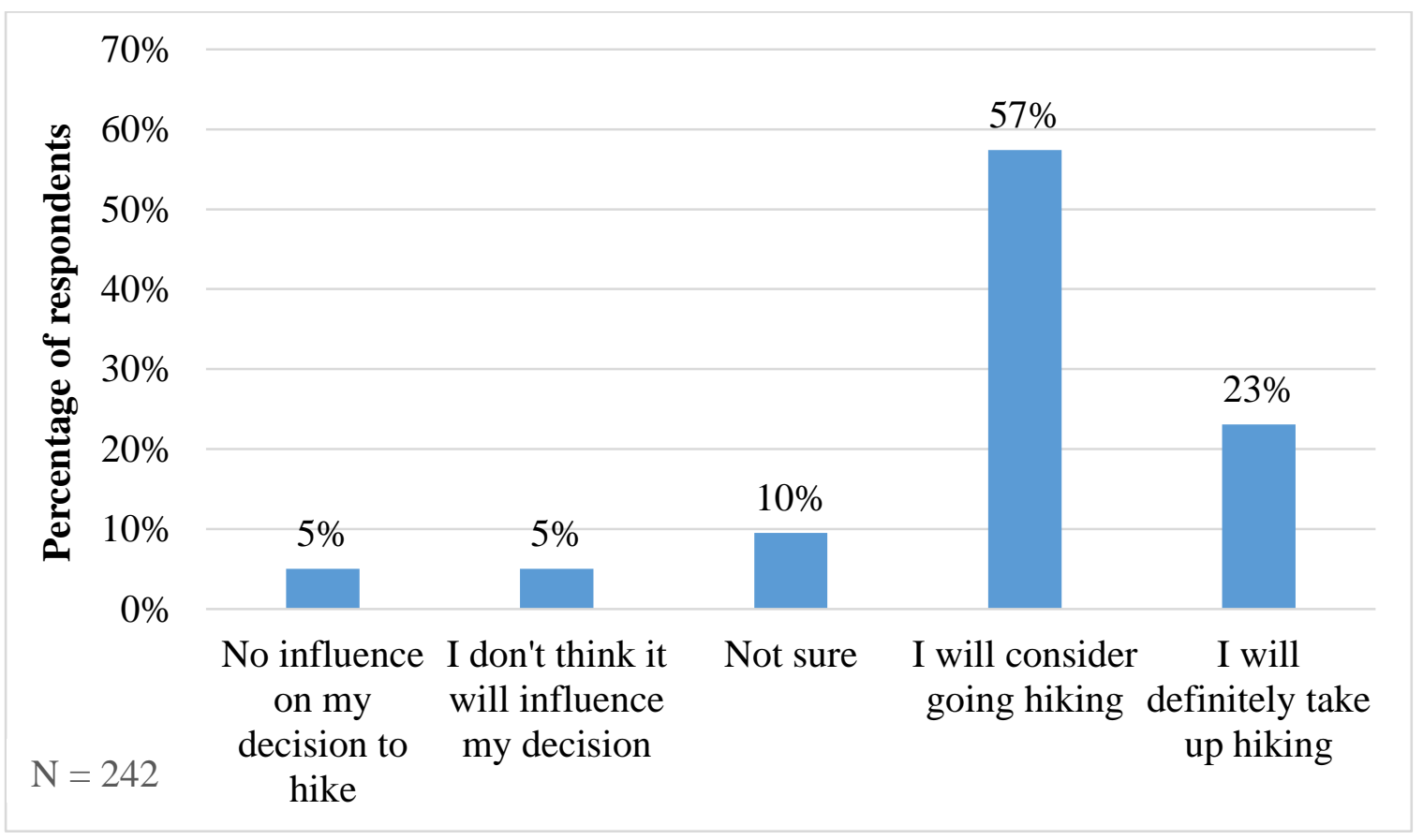

The results show that the accreditation of hiking trails on a large scale may influence nonhikers' decisions regarding hiking.

\section{Hikers}

As seen in Figure 4, 64\% of hikers reported trail accreditation would likely positively influence their hiking buying behaviour, either by considering hiking more frequently, or actually intending on doing so. More than a quarter (27\%) said a widespread presence of trail accreditation would lead to an increase in purchases of hiking tourism products, while $37 \%$ would consider increasing the purchase of hiking tourism products. Less than $10 \%$ of hikers were certain accreditation would have no influence on their current hiking activity levels. 
Accreditation of trails could therefore positively influence future activity levels of those already hiking.

\section{Figure 4: Influence of accreditation on future purchase behaviour of hikers}

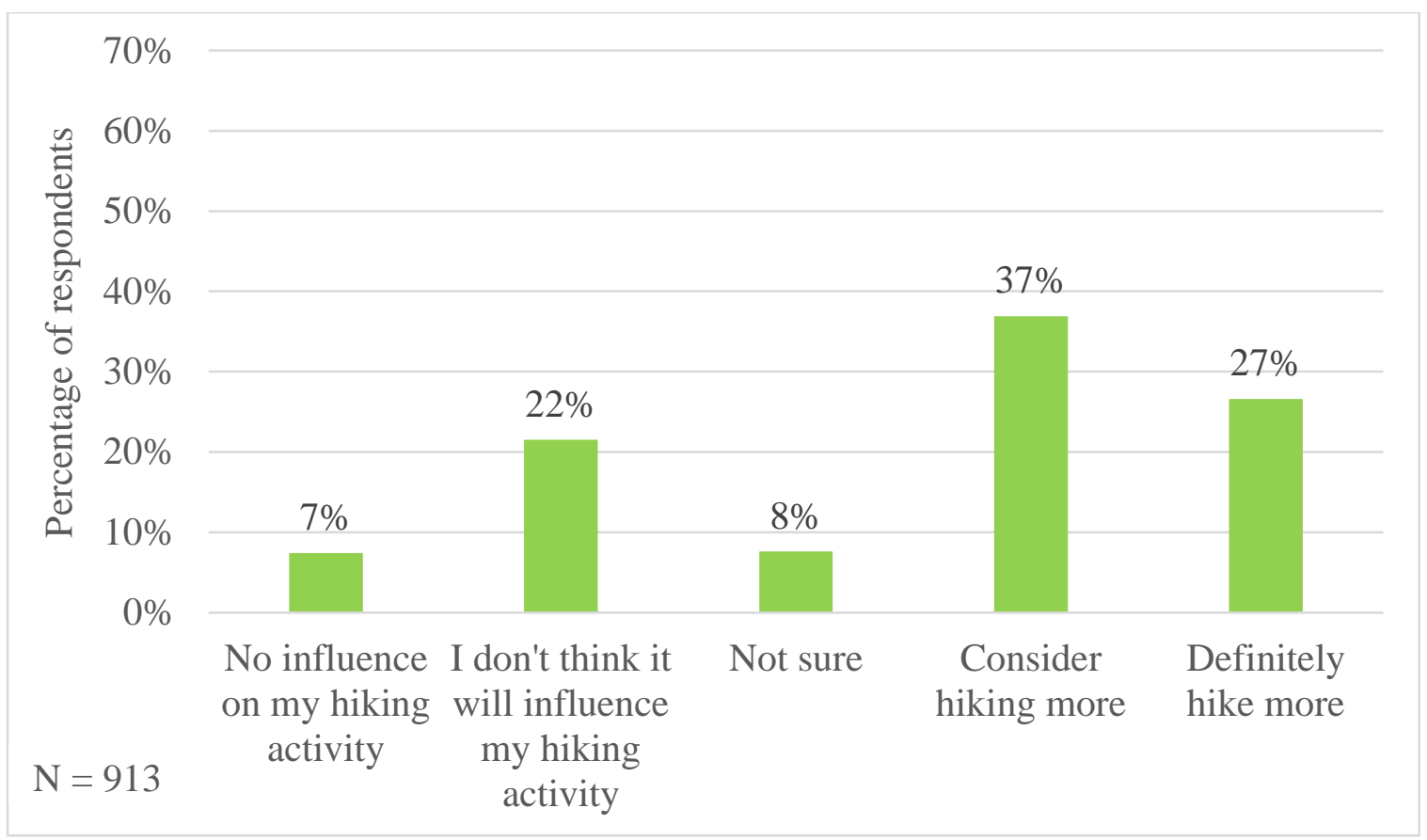

\section{$\underline{\text { Discussion }}$}

Though current literature is not in agreement as to whether accreditation can influence consumer decision making and buying behaviour (Foster, 2003; Leonard, 2011; Lacher, 2012; Marchoo et al., 2014), this study has proven such link to exist. The importance of independent accreditation of trails was measured and found to be perceived as a valuable discriminator in decision making amongst hikers. What's more, infrequent hikers depend more on information and less on their past experiences to assess whether a trail should be embarked on and to make the appropriate preparations for the trip. This was proved by the finding that accreditation was regarded more important to infrequent hikers. These findings are supported by Kerstetter and Cho (2004), who found evidence from previous studies where a negative relationship was observed between past experience and information search (as experience with a destination increases, search for external information decreases). Past experience is one of the most influential factors in the decision-making process, effecting the acquisition of incoming information from external sources. 
Hikers may rely on third parties for aiding in the decision making process with regards to trails - to varying degrees. The fact that a hiker books through a third party does not necessarily excuse him/her from the task of selecting a trail in the first place. A third party may be able to provide additional information about the trail, share previous clients' experiences and offer advice when alternatives are considered. Those who book directly with trail owners may have different information needs and may carry different perceptions about the importance of the accreditation of trails. This study suggests that accreditation becomes more important when hikers book directly with trail owners. In the process of transforming ownership in tourism and leisure in accordance with the National Development Plan in South Africa, such information is very important to inform decisions made by aspiring local business owners aiming to offer hiking products to consumers. Local entrepreneurs in especially rural areas could potentially tap into this leisure market through responsible utilisation of appropriate natural resources in the area. The issue of capacity building then becomes an important consideration, where government support to such leisure providers should include knowledge building on consumer-relevant product development. Support should also include skills development and where possible support in kin to assist in product development that will meet the standards of the accreditation system.

Non-hikers' responses towards trail accreditation also indicate that Green Flag may encourage a notable improvement in participation in hiking amongst nature and outdoor enthusiasts not already hiking. This becomes particularly relevant in the context of transforming hiking participation in South Africa into a more inclusive leisure activity, connecting society with nature through creating awareness of hiking as a desirable leisure activity. This links to government's expressed interest (especially from a tourism perspective) to create a culture of travel among previously disadvantaged population groups. Similar to other types of leisure, sport and tourism activities, curriculum in Life Orientation and Tourism as subjects create the ideal problem to expose learners to these concepts and plant the seeds for a growing interest in outdoor leisure pursuits later in life. As a relatively inexpensive and widely available activity, hiking is a suitable activity to introduce people to outdoor leisure.

Judging by the quality, types and number of hiking trails available to consumers, South Africa has a golden opportunity to meaningfully grow this leisure offering if it can manage to overcome the challenges of a relative lack of interest by policy decision makers and the 
deterioration in product quality. The results of this study show that Green Flag could make a significant contribution towards increasing participation in hiking in South Africa by acting as a trustworthy advisor on the quality and conditions of trails to the consumer. Not only may it support increased participation from a broader base of the South African society, but a country-wide implementation of Green Flag could promote future development of this leisure activity in a responsible manner. It is therefore recommended that trail owners and policy makers adopt independent trail accreditation for purposes of quality, sustainability and greater participation from society.

\section{$\underline{\text { References }}$}

Bergin, S., \& Jago, L.K. (1999). Accreditation of adventure tour operators: The consumer perspective. CAUTHE 1999: Delighting the Senses, Canberra, Ninth Australian Tourism and Hospitality Research Conference (pp. 223-234).

Buckley, R. (2002). Tourism ecolabels. Annals of Tourism Research, 29(1):183-208.

BuzzFeed Inc. (2015). 16 Astounding Backpacking Trips To Add To Your Bucket List.

Available from: http://www.buzzfeed.com/ariannarebolini/astoundingbackpackingtrips.\#kvQMJjGXP.

Chia-Jung, C., \& Pei-Chun, C. (2014). Preferences and Willingness to Pay for Green Hotel Attributes in Tourist Choice Behavior: The Case of Taiwan. Journal of Travel \& Tourism Marketing, 31(8):937-957.

Font, X. (2002). Environmental certification in tourism and hospitality: progress, process and prospects. Tourism Management, 23(3):197-205.

Foster, D. (2003). The Customer's perception of tourism accreditation. Melbourne: RMIT University, Centre for Management Quality Research. [Online] Available from: http://mams.rmit.edu.au/2ulaujpi756m.pdf [Downloaded: 2014-05-13].

Green Flag Trails. (2015). Green Flag Trails website. Retrieved from: http://www.greenflagtrails.co.za. 
hellawella.com. (2015). Take a hike 30 most spectacular hiking trails around the world. Retrieved from: http://www.hellawella.com/take-hike-world\%E2\%80\%99s-30mostlifechanging-treks.

Kerstetter, D., \& Cho, M. (2004). Prior knowledge, credibility and information search. Annals of Tourism Research, 31(4):961-985.

Lacher, R. (2012). SERIOUS TOURISM AND CONSUMER PREFERENCE FOR SUSTAINABLE TOURISM CERTIFICATIONS. Unpublished doctoral thesis. Clemson: Clemson University.

Leonard, D. (2011). A study into the motivations for participation in environmental certification schemes by the tourist accommodation sector. Bachelor of Business Administration. Vienna, Austria: Modul University.

Lonely Planet. (2015). South Africa's top five multiday hikes_Article _ South Africa - Lonely Planet Visa. Retrieved from: http://www.lonelyplanet.com/campaigns/visaanywhere/southafrica/article/south-africas-top-five-multiday-hikes/

Marchoo, W., Butcher, K., \& Watkins, M. (2014). Tour Booking: Do Travelers Respond to Tourism Accreditation and Codes of Ethics Initiatives? Journal of Travel \& Tourism Marketing, 31(1):16-36.

National Geographic Society. (2014). World's Best Hikes: Epic Trails. Retrieved from: https://www.nationalgeographic.com/adventure/lists/hiking-backpacking/worlds-best-grailtrails/.

Placestoseeinyourlifetime.com. (2014). Top 10 Hiking Trails in the World_Places To See In Your Lifetime. Retrieved from: http://www.placestoseeinyourlifetime.com/top-10-hikingtrails-in-the-world-2411/.

Walkopedia. (2015). Walkopedia - Best walks, hikes and treks in South Africa. Retrieved from: http://www.walkopedia.net/walks/full-list/country-list.asp?country= South\%20Africa. 